\title{
Lifetime Lubricant Use among a Nationally Representative Sample of Lesbian- and Bisexual-Identified Women in the United States
}

\author{
Devon J. Hensel, $\mathrm{PhD}^{1,2}$ \\ Vanessa Schick, $\mathrm{PhD}^{3}$ \\ Debby Herbenick, $\mathrm{PhD}, \mathrm{MPH}^{4}$ \\ Brian Dodge, $\mathrm{PhD}^{4}$ \\ Michael Reece, $\mathrm{PhD}^{4}$ \\ Stephanie Sanders, $\mathrm{PhD}^{5,6}$ \\ J. Dennis Fortenberry, MD, MS $^{1}$
}
${ }^{1}$ Division of Adolescent Medicine, Indiana University School of Medicine, Indianapolis, IN, USA
${ }^{2}$ Department of Sociology, Indiana University Purdue University-Indianapolis, Indianapolis, IN, USA
${ }^{3}$ University of Texas, Houston, TX, USA
${ }^{4}$ Center for Sexual Health Promotion, Indiana University, Bloomington, IN, USA
${ }^{5}$ The Kinsey Institute for Research on Sex, Gender and Reproduction, Indiana University,
Bloomington, IN, USA
${ }^{6}$ Department of Gender Studies, Indiana University, Bloomington, IN, USA

\section{Correspondence should be addressed to: Debby Herbenick, PhD, MPH, Center for Sexual Health Promotion, Indiana University, SPH 116, Bloomington, IN, 47405, USA, debby@indiana.edu}

\section{Manuscript words: 3693}

Keywords: lesbian women, bisexual women, lubricant, sexual behavior, nationally representative sample

This is the author's manuscript of the article published in final edited form as:

Hensel, D. J., Schick, V., Herbenick, D., Dodge, B., Reece, M., Sanders, S. A., \& Fortenberry, J. D. (2015). Lifetime Lubricant Use among a Nationally Representative Sample of Lesbian- and Bisexual-Identified Women in the United States. The Journal of Sexual Medicine, 12(5), 1257-1266. http://doi.org/10.1111/jsm.12873 


\begin{abstract}
Introduction. The diversity in self-identified lesbian and bisexual women's sexual interactions necessitates better understanding how and when they integrate personal lubricant into different experiences. However, little is known about lesbian and bisexual women's lifetime lubricant use, particularly in a nationally representative sample.
\end{abstract}

Aims. The aim of this study was to examine the prevalence and characteristics of lubricant use, among adult lesbian and bisexual women in the United States.

Methods. Data are drawn from a subset of lesbian and bisexual participants who participated in the 2012 National Survey of Sexual Health and Behavior, an online questionnaire administered to a nationally representative probability sample of U.S. adults ages 18 and older.

Main Outcome Measures. We examined socio-demographic characteristics, recent and lifetime lubricant use, lubricant use in associated with specific sexual behaviors and condom use, frequency of use, motivations for use, as well as perception of lubricant when used.

Results. A majority of lesbian- (60.1\%) and bisexual-identified (77.1\%) women reported ever using lubricant; $25.7 \%$ of lesbian women and $32.7 \%$ of bisexual women used it in the last 30 days. Across most age groups, lubricant was commonly used during partnered sexual play, partnered sexual intercourse or when a vibrator/dildo was used. Lesbian and bisexual women reported using lubricants to increase arousal/sexual pleasure/desire, to make sex more fun, or to increase physical comfort during sex.

Conclusions. Lubricant use is identified as a part of lesbian and bisexual women's sexual experience across the life span, as a part of both solo and partnered experiences. As part of evolving sexual health assessments, clinicians and health educators may find value in integrating lubricant-focused conversation with their lesbian and bisexual patients and clients, particularly 


\section{INTRODUCTION}

Recent literature has begun to illuminate the considerable diversity in sexual attitudes, behaviors and relationships among self-identified lesbian and bisexual women. ${ }^{1}$ In response to historical misunderstanding of what constitutes "sex" between lesbian and bisexual women and their partners, researchers have begun to pay particularly attention to the specific solo and partnered behaviors that lesbian and bisexual women integrate into their sexual repertoire. These behaviors include performing or receiving oral sex on the vagina or anus, performing or receiving vaginal or anal penetration with fingers or fists, mutual masturbation, genital rubbing, vaginal penetration by a penis, as well as vibrator/dildo use and other sex toy use in or around the vagina or anus. ${ }^{2-8}$ Younger women typically report participating in fewer penetrative behaviors, while women in long term relationships often engage in a broader array of behaviors. ${ }^{7}$ Such a wide variety of behaviors presents unique sexual health challenges among lesbian and bisexual women, ${ }^{9}$ as a woman's use, care and treatment of her vagina and genital area has important implications for her sexual function, sexual pleasure and fertility, as well as her vulnerability to a variety of sexually transmitted infections, including HIV. ${ }^{10-12}$ Thus, understanding how, when and for what reasons lesbian and bisexual women have used personal lubricants during their sexual interactions is important for supporting their sexual health.

Scientific literature describing women's lube use is growing. Nationally representative surveys of U.S. adults have shown than a majority (62.0\% - 65.5\%) of women aged 18 to 59 years have ever used a lubricant for solo and/or partnered activities, with a quarter of the same age group doing so in the last month. ${ }^{13,14}$ In the same data, about a third of adult women indicate using lubricant during partnered and solo sexual behaviors during their most recent sexual encounter, both with and without condom use. ${ }^{15-17}$ Nationally representative samples of lesbian and bisexual women suggest similarly high levels of lifetime lube use, ${ }^{18}$ with $25 \%$ of 
lesbian-identified women and $40 \%$ of bisexual-identified women reporting lubricant use in the past month. ${ }^{3}$ Additional work has demonstrated that lubricant is most commonly applied to a woman's genitals, her partner's genitals or to her partner's fingers; half of women report selfapplication, and a third indicate partner application. ${ }^{15-17}$

Existing research suggests that women may use lubricants for a number of reasons, ${ }^{14}$ such as increasing physical comfort, increasing sexual pleasure and satisfaction during vaginal or anal penetration, ${ }^{16}$ or to increase vaginal wetness and orgasmic response during sex. ${ }^{17,19}$ Lubricant may also be recommended to women for the reduction of pain, and the risk of vaginal or anal tearing, as well as the amelioration of vaginal dryness. ${ }^{19-21}$ Moreover, various public health initiatives recommend the addition of water- or silicone-based lubricant to male condomprotected sex acts as a means of reducing male condom failure, such as breakage. ${ }^{22}$

Although these studies provide general evidence as to the widespread use and factors associated with women's lubricant use, little is known about the frequency and context of selfidentified lesbian and bisexual women's lubricant use over the lifespan, their perceptions of lubricants, or their motivations for using lubricants. One reason for this paucity can be linked to the general challenges of recruiting lesbian, gay, bisexual and transgendered (LGBT) individuals. The absence of a sampling frame for LGBT individuals (e.g. a list of all population members) often compels researchers interested in these groups to rely upon more feasible nonprobability based recruitment methods, such as convenience sampling. ${ }^{23}$ The bias introduced in these methods can make it difficult to reliably generalize findings about beyond the specific individuals in a given sample. Therefore, an important contribution of the current study is our use of a probability sampling approach, making these results nationally representative of selfidentified lesbian and bisexual women's lubricant use patterns.

A second factor in this limited understanding is associated with inconsistency in the manner in which studies define sexual orientation and/or sexual identity. Specifically, a large 
number of previous studies have collapsed "lesbians" and "bisexual" women into one monolithic category designated as "women who have sex with women (WSW)." ${ }^{24}$ This false assumption of similarity between these two groups ${ }^{25}$ both masks differences in lesbian and bisexual women's unique preferences and choices important to understanding their sexual health, and obscures elements of their sexual behavior vital to the success of public health and/or education intervention and research. ${ }^{24}$ Thus, an additional strength of the current study is our ability to assess lubricant use patterns and motivations separately among lesbian and bisexual women.

This more refined understanding could enhance the design of lesbian- or bisexualwomen tailored STI prevention programs. For example, although having female-only versus both male and female sexual partners creates different types of STI risk between lesbian and bisexual women, ${ }^{26}$ lubricant use could be positioned in both groups to reduce any vaginal trauma-associated STI exposure (e.g. tearing or abrasions) that might occur during common sexual activities. Such use could be particularly important among lesbian women, who can falsely believe STIs are less likely to be transmitted between women. ${ }^{8}$ Moreover, detailed data could assist clinicians and other health professionals in their efforts to address lesbian and bisexual patients' lubricant-related to lubricant-related questions or concerns. ${ }^{17}$

Moreover, additional data could assist health professionals in their efforts to address lesbian and bisexual patients' lubricant-related questions or lubricant-related concerns across different life stages. ${ }^{17}$ For example, lubricant use could be important to facilitating comfort and pleasure during younger lesbian and bisexual women's participation in more exploratory-type sexual behaviors or during midlife as some lesbian and bisexual women initiate new sexual relationships. Likewise, lubricant could be an important adjunct among those who experience pain during solo or partnered sex, or for those who want to increase sexual pleasure during solo sex. 
Aims

The overall aim of this study was to assess the prevalence of and characteristics associated with lesbian- and bisexually-identified women's lifetime lubricant use. Specifically, we examined demographic factors associated with lifetime lubricant use, the reasons for which lesbian and bisexual women started using lubricant, the sexual contexts associated with recent lubricant use, and women's frequency of use and perceptions of lubricant use during specific sexual activities.

\section{METHODS}

\section{Data Collection Procedure}

Data presented are from the 2012 National Survey of Sexual Health and Behavior (NSSHB). The NSSHB is a population-based cross-sectional survey of adult women and men in the United States. Data were collected during October and November 2012, via the KnowledgePanel of GfK Research (GfK) (Menlo Park, California). Research panels accessed through GfK are based on a national probability sample established using both random digit dialing (RDD) and an address-based sampling (ABS) frame. ABS involves the probability sampling of a frame of residential addresses in the US derived from the US Postal Service's Delivery Sequence File, a system which contains detailed information on every mail deliverable address in the US. Collectively, the sampling frame from which participants are recruited covers approximately $98 \%$ of all US households. Randomly selected addresses were recruited to the research panel through a series of mailings and subsequently by telephone follow-ups to nonresponders when possible. More information about these methods can be found on GfK's website. $^{27}$

The sampling frame involved both heterosexual and LBGT individuals, all of whom received a recruitment message from GfK that provided a brief description of the NSSHB and 
invited them to participate. A total of 6,175 were included in the initial sampling frame, with $61.5 \%(\mathrm{~N}=4,020)$ viewing the informed consent. The majority of those individuals, $81.7 \%(\mathrm{~N}=$ $3,285)$ consented to participate, of which 3,138 (95.5\%) individuals completed the survey. Thus, a total of $78.1 \%$ of people who viewed the consent form completed the entire survey.

For the current paper, we retained individuals $(\mathrm{N}=360)$ who identified themselves as women, and who additionally indicated their sexual orientation to be homosexual/lesbian or bisexual. Post stratification weights - one specific to heterosexuals and one specific to LGBT individuals - were generated to correct for sources of sampling, as well as non-sampling error, using demographic distributions from the most recent data available from the Current Population Survey (CPS). Thus, because these weights include adjustments to population level characteristics, their application in statistical models allows nationally representative conclusions. In the current paper, the LGBT weight was applied to all data. The Institutional Review Board at Indiana University - Bloomington reviewed and approved all protocols associated with this study.

\section{Measures}

Socio-demographic characteristics included, age (18-24, 25-29, 30-39, 40-49, 50-59 and $60+$ ), education level (less than high school, high school/GED, some college or associates degree, college degree or higher), race/ethnicity (White/Non-Hispanic, Black/Non-Hispanics, Other/Non-Hispanic, Hispanic and Multiple races/Non-Hispanic) and relationships status (single and not currently dating, single and dating, in a relationship but not living together, living with relationship partner, married and living together, married but not living together.

Recency of lubricant use was assessed both overall, and in specific sexual contexts (during solo masturbation, during partnered sex, during partnered intercourse, with a condom, with a vibrator or with a dildo) (ever used: no/yes, and recency: past 30 days, past 90 days, past 
12 months and more than a year ago). For any lesbian and bisexual women who reported lubricant use in the past 90 days, we also examined the frequency of overall and behavior context specific use (once or twice, 3-5 times, 6-10 times, more than 10 times). For additional comparison, we also examined how frequently lubricant was used out of the last ten times participants reported masturbation, any oral sex, any vaginal sex, and any anal sex.

Finally, lesbian and bisexual women also reported on their overall reasons (e.g. curiosity, for fun, to manage vaginal pain), and sexual activity specific reasons (e.g. partner suggested, friend recommended, doctor/nurse recommended), for lubricant use (all: no/yes), as well as on their agreement with reasons for using lubricant during sexual activities (e.g. makes it easier to feel aroused or makes sex feel better) (all strongly disagree to strongly agree).

\section{Data Analysis}

Frequencies and descriptive statistics were used to examine the prevalence of lesbian and bisexual women's lubricant use rates, as well as their perception of and reasons for using lubricants. In addition, we used a series of logistic regression models to predict sociodemographic factors associated with the likelihood of lesbian and bisexual women's perceptions of lubricant use and their likelihood of using lubricant. (SPSS, 21.0).

\section{RESULTS}

Overall Participant Characteristics and Lubricant Use.

Table 1 provides a descriptive overview of the demographics of our sample. Participants who identified as a lesbian tended to be older than participants who self-identified as bisexual. While almost $75 \%$ of the participants who identified as bisexual were under the age of 40 , over half of the participants who identified as a lesbian were over the age of 40 (Table 1). Both lesbian and bisexual-identified participants reported at least some college. While over half of the 
participants reported their race/ethnicity as White/Non-Hispanic, a sizable minority of participants reported that they were Black, Non-Hispanic or Hispanic. The highest percentage of participants reported that they were currently living with their relationship partner.

Relationship status was a significant predictor of lubricant use for both lesbian and bisexual-identified participants. Compared to participants who were single and not dating, the odds of lubricant use significantly increased for participants who were married and living together $(p<.05)$. For bisexual participants, the odds of lubricant use also increased for those who were single and dating relative to those who were single and not dating $(O R=15.47, p<.05)$. Among lesbian-identified women, Black/Non-Hispanic participants were more likely than White/Non-Hispanic participants $(\mathrm{OR}=1.10 ; p<.001)$ to have ever used lubricant. Age and education were not significantly associated with lubricant use history for any participants.

\section{Overall and Sexual Behavior Context and Recency of Lubricant Use.}

As shown in Table 2, most lesbian-identified participants $(60.1 \%, \mathrm{~N}=76)$ stated they had ever used lubricant at some point in their lifetime. The highest prevalence of use was reported in the 50-59 year old group (74.5\%) and the lowest prevalence of use in the 25-29 year old group (47.7\%), and half of all other age groups (54.3\% to $57.5 \%)$ also reported lifetime lubricant use. As shown in Table 3, over three quarters of bisexual-identified participants $(77.1 \%, N=170)$ noted lifetime lubricant use. Highest use prevalence in the 30-39 year old group (83.1\%) and lowest use in the 50-60 year old group (62.3\%). As compared to lesbian-identified participants, more bisexual participants in other age groups (63.4\% to $82.6 \%)$ reported lifetime lubricant use. In terms of more recent lubricant-associated behaviors, among all participants, lubricant was most frequently reported in the past 30 days as compared to all other time frames. For both lesbian (2.9\%) and bisexual (14.3\%) women, overall past month lubricant use was least common during condom use. In addition to solo masturbation among bisexual women (18.0\%) 
and dildo use among lesbian women (18.4\%), partnered sexual play (lesbian: 17.4\%; bisexual: 18.0\%) and partnered intercourse (lesbian: 16.0\%; bisexual: 20.7\%) were among the most common past month lubricant associated activities

Controlling for age, among those 18 to 24 years, about a third of both lesbian (30.8\%) and bisexual (30.8\%) participants reported partnered intercourse in the past 30 days. In the same age group, however, partnered sexual play was also common among lesbians (31.6\%), whereas solo masturbation was more common among bisexual women (31.0\%). Dildo use was a common context for lubricant use among lesbian women between 30 and 59 (16.6\% - 24.9\%), and bisexual women between 25 and 20 years (19.5\%). Lubricant use during solo masturbation occurred among bisexual women across the lifespan, with between ten percent and one third reporting use in the last month. Interestingly, past month lubricant use was low among lesbian women over 60 years, with less than $15 \%$ of participants reporting it in the context of any behavior. In comparison, far more bisexual women over 60 (between $2 \%$ and 27.6\%) reported past month lubricant use in the context of solo and partnered behaviors.

\section{Frequency of Lubricant Use.}

As shown in Table 3, bisexual and lesbian participants differed in the frequency with which they reported lubricant in the past 90 days for different behaviors. Overall, bisexual women reported greater frequency of lubricant use across behaviors as compared to lesbian women. Bisexual participants reported using lubricant more than ten times for solo masturbation (39.67\%), during partnered intercourse (38.27\%) and with a vibrator (36.33\%). However, between a third and half of lesbian women reported using lubricant only once or twice during solo masturbation (40.33\%), during partnered intercourse (40.97\%), with a vibrator (38.79\%) and with a dildo (40.45\%). 
Reasons for Lubricant Use.

Lesbian and bisexual women exhibited some similarities in their reasons for first beginning to use lubricant (Table 4). About $40 \%$ of both groups noted use was initiated "for fun" and about $30 \%$ of both groups cited sexual event associated reasons, including foreplay enhancement, partner desire, to increase wetness and to increase sensation, as motivations for first use. More bisexual (42.4\%) than lesbian (30.0\%) reported being curious about lubricant. Interestingly, while almost $60 \%$ of lesbian women suggested use was motivated by a desire to make sex more comfortable, only $15.1 \%$ of them endorsed lube to manage vaginal pain. Bisexual women more commonly reported lubricant for risk reduction purposes, such as vaginal tearing or condom breakage. Very few lesbian or bisexual women began using lube during sexual activities out of family member or clinical recommendation.

Average Use Frequency, Perceptions of and Experiences with Lubricant Use.

Both lesbian and bisexual women reported using lubricants on average about one or two times out of the last ten times they engaged in masturbation, oral sex or vaginal sex. Increased age was associated with more frequent lube use during vaginal sex among lesbian women $(O R=2.81)$. Bisexual women reported using lubricant the majority of the time - about eight of the last ten - they participated in anal intercourse.

The majority of bisexual and lesbian-identified participants (Table 5) reported that lubricant makes "it easier to feel aroused" (bisexual: 60.5\%; lesbian: 75.6\%), "sex feel better" (bisexual: 65.7\%; lesbian: 84.6\%) and "sex more comfortable" (bisexual: 80.7\%; lesbian: 87.7\%) Older bisexual-identified participants significantly more likely than younger participants to indicate that lubricant makes sex feel better $(O R=1.05, p<.01)$. Older lesbian-identified participants were significantly more likely than younger participants to endorse the statement 
that using lubricant during sexual activities is "only for older people" $(O R=1.09, p<.05)$ and/or it "makes sex more comfortable" (OR=1.11, p<.001).

\section{DISCUSSION}

This study investigated the lifetime characteristics of lubricant use among lesbian- and bisexual-identified women. Consistent with other nationally representative studies examining lubricant in women in general, as well as those among lesbian and bisexual women, 3,15,16,18-21 we found that a majority of both lesbian (60.1\%) and bisexual (77.1\%) reported ever using lubricant, with fewer women (lesbian: 25.3\%; bisexual: $32.7 \%$ ) reporting any use in the past 30 days. These data extend existing studies by describing the considerable diversity in how often lesbian and bisexual women have used lubricant, in the context of which partnered and nonpartnered sexual activities they have used lubricant, their general and sexual motivations for lubricant use initiation, and their perceptions of sexual events during which lubricant is used. Importantly, we also highlight differences between lesbian and bisexual women on these attributes.

Demographic differences in lifetime lubricant use may reflect the different purposes that lubricant serves at different points in the lifespan. For example, bisexual women who were single and dating, and lesbians who were married and living with their relationship partner were more likely to ever having reported used lubricant. While we did not examine relationship length, these findings may reflect differences in the types of sexual behaviors that partners engage at different times during their relationships. This latter point is also reflected in how age impacts the diversity of solo and partnered behaviors during which lesbian and bisexual women employed lubricant use. For example, partnered foreplay/sexual play and partnered intercourse were the overall most common past month contexts during which lesbian and bisexual women reported, with less use in older age groups. Likewise, lubricant use in association with solo 
masturbation for bisexual women and dildo use for lesbian women increased. In addition, bisexual participants used lubricant the most frequently for solo masturbation and partnered intercourse, whereas lesbian reported using lubricant quite infrequently for any activity.

Lesbian and bisexual women reported a variety of reasons for commencing lubricant use, the most common of which were out of curiosity or fun. As with prior studies, women also cited sexual-event specific reasons, including enhancement, partner desire, to increase wetness and to increase sensation. ${ }^{16,17,19}$ Risk reduction motivations, including decreasing vaginal tearing or condom breakage, ${ }^{19-22}$ was more commonly reported among bisexual women than lesbian women, possibly out of differing perceptions in sexual risk exposure history ${ }^{26}$ or in beliefs about STI transfer between women. ${ }^{8}$ Increasing sexual comfort was a common motivation for lesbian women, despite the fact that very few selected lubricant to reduce sexual pain. This latter point could suggest an important spectrum of sensations for which lubricant is used besides those associated typically with either "sexual pleasure" or "sexual pain," particularly in light of the fact that a majority of lesbian and bisexual women agreed with the idea that lubricant could be used to both get aroused, and to make sex feel better. However, more research is needed in regard to lesbian and bisexual identified women's experiences of pain during sex and the many ways they seek to address painful sex. Recent research suggests that women, regardless of sexual orientation, who partner with men are more likely to report pain during sex, likely because of a greater emphasis on vaginal intercourse during their partnered sex. ${ }^{28}$ Subsequent population-level research should explore this as well as steps that women take to address painful sex, including lubricant use, broadening the range of sexual behaviors, communication, and so on.

\section{IMPLICATIONS}


Our findings have several significant implications for both research and clinical practice. Collectively, our results underscore that lubricant continues to be important as self-identified lesbian and bisexual women shift in and out of different life stages. Such ongoing important could be linked at younger ages to lesbian and bisexual women's participation in exploratorytype behaviors, and in midlife to lesbian and bisexual women's initiation of new sexual relationships following the death of, or divorce from, a long-term partner. Likewise, lubricant could be used among non-partnered lesbian and bisexual women during midlife as a means of meeting one's own sexual needs, or by those in relationships who desire an adjunct to relationship-focused sexuality. Better understanding the behavioral context, recency, frequency and motivations for lubricant use could help clinicians and educators anticipate how lesbian and bisexual patients and clients will use lubricant, as well as when these patterns may change as life circumstances change. For example, lubricant increase sexual comfort as they engage new sexual behaviors in younger years, or as they combat age-related changes to the vagina. Importantly, this information could also help clinicians and educators proactively design risk reduction programs as lesbian and bisexual women experience physical, emotional and relationship changes across the life span. For example, lubricant could be an important STI risk reduction tool as lesbian and bisexual women acquire new partners, either in younger years or in midlife.

\section{Strengths and Limitations}

As with all research, this study has both strengths and limitations. Similar to other crosssectional survey studies, participants were not able to clarify survey items assessing lubricant use or sexual behaviors that they may have found unclear. Moreover, like other studies of sexual behavior, some participant self-selection is possible. Although the sampling methods were designed to ensure similarity between responders and non-responders on key socio- 
demographic variables, we are unable to assess the extent to which participants were different on study variables from those who either did not respond to the recruitment messages or those who responded and chose not to participate. We also did not assess the length of time participants engaged in the sexual activities with which they reported using lube. Moreover, while the majority of participants in the sample reported their last sexual event occurred with another woman, we did not assess the gender of sexual partner for lifetime sexual behaviors or for lubricant use. Finally, some lubricant use recency questions were assessed for general sexual activity use (e.g. "partnered intercourse") rather than within the context of specific behaviors.

These limitations notwithstanding, this study invokes two important strengths over prior literature, such as use of nationally representative, probability-based sampling techniques over more traditionally used convenience samples of sexual minority individuals. ${ }^{23}$ We also conducted detailed analyses of lubricant use separately for self-identified lesbian and bisexual women, rather than assuming similarity between all "women who have sex with women." ${ }^{24}$ Since the ability to design and implement health promotion or prevention programs specifically targeting lesbian and bisexual women is contingent upon data that reliably document the context of risk and/or protective sexual activity, ${ }^{7}$ these data provide important lifespan information about lubricant use. They highlight, for example, the marked diversity in motivations for lubricant use, the behaviors during which they use lubricant, and the aspects of sex that improve as a result of lubricant use. This study reinforces the growing body of evidence as to the need for research and clinical policy need to be attentive to these potential differences between self-identified lesbian and bisexual women, as well as between lesbian and bisexual women and heterosexual women, when engaging "women who have sex with women" as clients in practice or as participants in research studies. ${ }^{25}$ 


\section{REFERENCES}

1. Fassinger RE, Arseneau JR. Diverse women's sexualities. Psychology of women: A handbook of issues and theories. 2008:484-508.

2. Mercer $\mathrm{CH}$, Bailey JV, Johnson AM, et al. Women who report having sex with women: British national probability data on prevalence, sexual behaviors, and health outcomes. American Journal of Public Health. 2007;97(6):1126-1133.

3. Herbenick D, Reece M, Sanders SA, Dodge B, Ghassemi A, Fortenberry JD. Women's Vibrator Use in Sexual Partnerships: Results From a Nationally Representative Survey in the United States. Journal of Sex \& Marital Therapy. 2010/01/04 2010;36(1):49-65.

4. Bailey JV, Farquhar C, Owen C, Whittaker D. Sexual behaviour of lesbians and bisexual women. Sexually Transmitted Infections. April 1, 2003 2003;79(2):147-150.

5. Schick V, Herbenick D, Rosenberger JG, Reece M. Prevalence and Characteristics of Vibrator Use among Women who have Sex with Women. The Journal of Sexual Medicine. 2011;8(12):33063315.

6. Schick V, Herbenick D, Rosenberger JG, Reece M. Variations in the Sexual Repertoires of Bisexually-Identified Women from the United States and the United Kingdom. Journal of Bisexuality. 2012;12(2):198-213.

7. Schick V, Rosenberger JG, Herbenick D, Reece M. Sexual behaviour and risk reduction strategies among a multinational sample of women who have sex with women. Sexually Transmitted Infections. October 1, 2012 2012;88(6):407-412.

8. Marrazzo JM, Coffey P, Bingham A. Sexual practices, risk perception and knowledge of sexually transmitted disease risk among lesbian and bisexual women. Perspectives on sexual and reproductive health. 2005;37(1):6-12.

9. Mcnair R. Lesbian and bisexual women's sexual health. Aust Fam Physician. 2009;38:388-393.

10. Myer L, Denny L, Telerant R, de Souza M, Wright TC, Kuhn L. Bacterial vaginosis and susceptibility to HIV infection in South African women: a nested case-control study. Journal of Infectious Diseases. 2005;192(8):1372-1380.

11. Carroll N, Goldstein RS, Lo W, Mayer KH. Gynecological infections and sexual practices of Massachusetts lesbian and bisexual women. Journal of the Gay and Lesbian Medical Association. 1997;1(1):15-23.

12. Marrazzo JM, Gorgos LM. Emerging Sexual Health Issues Among Women Who Have Sex with Women. Current Infectious Disease Reports. Apr 2012 2012;14(2):204-211. 
13. Herbenick D, Reece M, Schick V, Sanders SA, Dodge B, Fortenberry JD. Sexual Behaviors, Relationships, and Perceived Health Status Among Adult Women in the United States: Results from a National Probability Sample. The Journal of Sexual Medicine. 2010;7:277-290.

14. Herbenick D, Reece M, Schick V, Sanders SA, Fortenberry JD. Women's Use and Perceptions of Commercial Lubricants: Prevalence and Characteristics in a Nationally Representative Sample of American Adults. The Journal of Sexual Medicine. 2014;11(3):642-652.

15. Herbenick D, Schick V, Reece $M$, et al. Characteristics of Condom and Lubricant Use among a Nationally Representative Probability Sample of Adults Ages 18-59 in the United States. The Journal of Sexual Medicine. 2013.

16. Herbenick D, Reece M, Hensel DJ, Sanders SA, Jozkowski K, Fortenberry JD. Association of Lubricant Use with Women's Sexual Pleasure, Sexual Satisfaction, and Genital Symptoms: A Prospective Daily Diary Study. The Journal of Sexual Medicine. 2011;8(1):202-212.

17. Jozkowski KN, Herbenick D, Schick V, Reece M, Sanders SA, Fortenberry JD. Women's Perceptions about Lubricant Use and Vaginal Wetness During Sexual Activities. The Journal of Sexual Medicine. 2013;10(2):484-492.

18. Fethers K, Marks C, Mindel A, Estcourt CS. Sexually transmitted infections and risk behaviours in women who have sex with women. Sexually Transmitted Infections. October 1, 2000 2000;76(5):345-349.

19. Braunstein S, Wijgert JVD. Preferences and practices related to vaginal lubrication: implications for microbicide acceptability and clinical testing. Journal of Women's Health. 2005;14(5):424433.

20. Sutton KS, Boyer SC, Goldfinger C, Ezer P, Pukall CF. To Lube or Not to Lube: Experiences and Perceptions of Lubricant Use in Women With and Without Dyspareunia. The Journal of Sexual Medicine. 2012;9(1):240-250.

21. Levin RJ. The ins and outs of vaginal lubrication. Sexual and Relationship Therapy. 2003;18(4):509-513.

22. Centers for Disease Control and Prevention. Condom Fact Sheet In Brief. Atlanta, GA2013.

23. Meyer IH, Wilson PA. Sampling lesbian, gay, and bisexual populations. Journal of Counseling Psychology. 2009;56(1):23.

24. Young RM, Meyer IH. The trouble with "MSM" and "WSW": Erasure of the sexual-minority person in public health discourse. American Journal of Public Health. 2005;95(7):1144.

25. Sanders S, Graham C, Milhausen R. Bisexual women differ from lesbian and heterosexual women on several sexuality measures. Sexualities. 2008;17:S157-S158.

26. Lindley LL, Kerby MB, Nicholson TJ, Lu N. Sexual Behaviors and Sexually Transmitted Infections Among Self-Identified Lesbian and Bisexual College Women. Journal of LGBT Health Research. 2008/06/20 2008;3(3):41-54.

27. Knowledge Networks. Methodological Papers, Presentations, and Articles on KnowledgePanel. 2014; http://www.knowledgenetworks.com/ganp/reviewer-info.html. Accessed October 5, 2014.

28. Blair KL, Pukall CF, SMith KB, Cappell J. Differential associations of communicatiom and love in heteroseual, lesbian, and bisexual women's perceptions and experiences of chronic vulvar and pelvic pain. J Sex Marital Ther, Published online ahead of print on August 25, 2014. 
Lesbian and bisexual women, 18

Table 1. Weighted Participant Socio-demographic Distribution by Lifetime Lubricant Use History

\begin{tabular}{|c|c|c|c|c|c|c|c|c|c|c|}
\hline \multirow[b]{3}{*}{ Characteristics } & \multicolumn{5}{|c|}{ Bisexual } & \multicolumn{5}{|c|}{ Lesbian } \\
\hline & \multicolumn{2}{|c|}{$\%(N)$} & \multirow{2}{*}{$\begin{array}{l}\text { No Lubricant } \\
\text { Use } \\
\% \\
\end{array}$} & \multirow[t]{2}{*}{$\begin{array}{l}\text { Lubricant } \\
\text { Use }\end{array}$} & \multirow{2}{*}{$\begin{array}{l}\text { Lubricant Use vs. } \\
\text { No Lubricant Use } \\
\text { Odds Ratio }(95 \% \mathrm{Cl})\end{array}$} & \multirow{2}{*}{\multicolumn{2}{|c|}{$\%(N)$}} & \multirow{3}{*}{$\begin{array}{l}\text { No Lubricant } \\
\text { Use } \\
\%\end{array}$} & \multirow[t]{2}{*}{$\begin{array}{l}\text { Lubricant } \\
\text { Use }\end{array}$} & \multirow{2}{*}{$\begin{array}{l}\text { Lubricant Use vs. } \\
\text { No Lubricant Use } \\
\text { Odds Ratio }(95 \% \mathrm{Cl})\end{array}$} \\
\hline & & & & & & & & & & \\
\hline \multicolumn{10}{|l|}{ Age } & \\
\hline $18-24$ (ref) & 25.7 & $(57)$ & $21.1 \%$ & $78.9 \%$ & $0.65(1.62)$ & 13.2 & $(18)$ & $41.2 \%$ & $58.8 \%$ & - \\
\hline $25-29$ & 20.4 & $(46)$ & $28.9 \%$ & $71.1 \%$ & $1.27(0.50-3.21)$ & 13.3 & $(18)$ & $52.6 \%$ & $47.4 \%$ & $0.63(0.16-2.42)$ \\
\hline $30-39$ & 28.1 & $(63)$ & $16.1 \%$ & $83.9 \%$ & $1.22(0.39-3.89)$ & 14.2 & $(19)$ & $42.1 \%$ & $57.9 \%$ & $0.93(0.24-3.53)$ \\
\hline $40-49$ & 13.0 & (29) & $17.2 \%$ & $82.8 \%$ & $0.43(0.15-1.25)$ & 22.3 & $(31)$ & $46.7 \%$ & $53.3 \%$ & $0.81(0.24-2.76)$ \\
\hline $50-59$ & 9.9 & $(22)$ & $36.4 \%$ & $63.6 \%$ & $0.45(0.08-2.52)$ & 30.3 & $(42)$ & $25.7 \%$ & $74.3 \%$ & $2.02(0.58-7.04)$ \\
\hline $60+$ & 2.9 & (6) & $33.3 \%$ & $66.7 \%$ & & 6.7 & (9) & $44.4 \%$ & $55.6 \%$ & $0.84(0.16-4.42)$ \\
\hline Education & & & & & - & & & & & \\
\hline Less than high school (ref) & 7.2 & $(16)$ & $13.3 \%$ & $86.7 \%$ & $0.25(0.06-1.10)$ & 5.5 & (8) & $42.9 \%$ & $57.1 \%$ & - \\
\hline High school or GED & 27.3 & $(61)$ & $41.0 \%$ & $59.0 \%$ & $1.94(0.40-9.37)$ & 16.6 & $(23)$ & $33.3 \%$ & $66.7 \%$ & $0.59(0.27-1.64)$ \\
\hline Some college or Associates Degree & 37.2 & $(83)$ & $8.6 \%$ & $91.4 \%$ & $0.53(0.12-2.33)$ & 40.5 & $(56)$ & $49.1 \%$ & $50.9 \%$ & $0.82(0.18-1.83)$ \\
\hline College Degree or Higher & 28.4 & $(63)$ & $25.4 \%$ & $74.6 \%$ & & 37.4 & $(51)$ & $30.0 \%$ & $70.0 \%$ & $0.43(0.39-1.86)$ \\
\hline \multicolumn{11}{|l|}{ Race/ethnicity } \\
\hline White, Non-Hispanic (ref) & 57.4 & $(128)$ & $22.8 \%$ & $77.2 \%$ & - & 61.1 & $(84)$ & $34.1 \%$ & $65.9 \%$ & - \\
\hline Black, Non-Hispanic & 19.1 & $(43)$ & $28.6 \%$ & $71.4 \%$ & $0.73(0.33-1.59)$ & 16.1 & $(22)$ & $86.7 \%$ & $13.3 \%$ & $1.10(1.02-1.41)^{\star \star \star \star}$ \\
\hline Other, Non-Hispanic & 1.5 & (3) & $0.0 \%$ & $100.0 \%$ & $3.49(0.06-197.00)$ & 3.4 & (5) & $20.0 \%$ & $80.0 \%$ & $3.29(0.22-48.23)$ \\
\hline Hispanic & 13.8 & $(31)$ & $30.0 \%$ & $70.0 \%$ & $0.69(0.29-1.67)$ & 11.9 & $(16)$ & $35.7 \%$ & $64.3 \%$ & $0.99(0.30-3.21)$ \\
\hline More than 2 Races, Non-Hispanic & 8.2 & (18) & $0.0 \%$ & $100.0 \%$ & - & 7.5 & $(10)$ & $40.0 \%$ & $60.0 \%$ & $0.81(0.21-3.06)$ \\
\hline \multicolumn{11}{|l|}{ Relationship Status } \\
\hline Single and not Dating (ref) & 19.2 & $(43)$ & $37.2 \%$ & $62.8 \%$ & - & 20.1 & $(28)$ & $53.8 \%$ & $46.2 \%$ & - \\
\hline Single and Dating & 7.4 & $(17)$ & $5.9 \%$ & $94.1 \%$ & $15.47(1.07-224.28)^{\star}$ & 7.0 & $(10)$ & $77.8 \%$ & $22.2 \%$ & $0.40(0.08-2.05)$ \\
\hline $\begin{array}{l}\text { In a Relationship but not Living } \\
\text { Together }\end{array}$ & 10.3 & $(23)$ & $18.2 \%$ & $81.8 \%$ & $2.40(0.70-8.22)$ & 15.4 & $(21)$ & $25.0 \%$ & $75.0 \%$ & $3.53(0.97-12.84)$ \\
\hline Living with Relationship Partner & 35.3 & $(79)$ & $25.6 \%$ & $74.4 \%$ & $1.64(0.73-3.65)$ & 45.2 & $(62)$ & $28.6 \%$ & $71.4 \%$ & $2.93(1.12-7.69)^{\star}$ \\
\hline Married and Living Together & 27.3 & $(61)$ & $16.7 \%$ & $83.3 \%$ & $2.94(1.17-7.43)^{\star}$ & 11.3 & $(16)$ & $60.0 \%$ & $40.0 \%$ & $0.73(0.20-2.63)$ \\
\hline Married but not Living Together & 0.5 & (1) & $0.0 \%$ & $100.0 \%$ & $1.59(0.03-100.45)$ & 1.0 & (1) & $0.0 \%$ & $100.0 \%$ & - \\
\hline
\end{tabular}

${ }^{*} p \leq .05,{ }^{* *} p \leq .01,{ }^{* * *} p \leq .005,{ }^{* * * *} p \leq .001$. 


\begin{tabular}{|c|c|c|c|c|c|c|c|c|c|c|c|c|c|c|c|}
\hline \multirow{3}{*}{ Recency of Lubricant Use \% (N) } & & \multicolumn{14}{|c|}{ Lesbian } \\
\hline & & \multicolumn{2}{|c|}{ Total Sample } & \multicolumn{2}{|c|}{$18-24$} & \multicolumn{2}{|c|}{$25-29$} & \multicolumn{2}{|c|}{$30-39$} & \multicolumn{2}{|c|}{$40-49$} & \multicolumn{2}{|c|}{$50-59$} & \multicolumn{2}{|c|}{$60+$} \\
\hline & & & & & & & & & $\%(\mathrm{~N})$ & & & & & & \\
\hline \multirow[t]{5}{*}{ Used a Lubricant } & Ever Used & 60.1 & (76) & 59.3 & (10) & 47.7 & (9) & 57.5 & (12) & 54.3 & (16) & 74.6 & (26) & 55.1 & (5) \\
\hline & Past 30 Days & 25.3 & (32) & 30.5 & (5) & 19.8 & (4) & 21.3 & (4) & 21.6 & $(6)$ & 33.4 & (12) & 17.4 & (2) \\
\hline & Past 90 Days & 5.3 & $(7)$ & 6.6 & (1) & 1.4 & (1) & 0.5 & $(1)$ & 13.5 & (4) & 2.1 & $(1)$ & 5.5 & (1) \\
\hline & Past 12 Months (Year) & 14.6 & (19) & 10.8 & (2) & 12.1 & (2) & 25.7 & $(5)$ & 15.6 & $(5)$ & 10.6 & $(4)$ & 15.0 & (1) \\
\hline & More than a Year Ago & 14.8 & (19) & 11.4 & (2) & 14.4 & (3) & 10.1 & $(2)$ & 3.6 & $(1)$ & 28.6 & $(10)$ & 17.2 & (2) \\
\hline \multirow[t]{5}{*}{ Used a Lubricant during Solo Masturbation } & Ever Used & 40.7 & (55) & 31.0 & (5) & 38.8 & (7) & 20.7 & (5) & 43.5 & (13) & 53.0 & (22) & 40.1 & (4) \\
\hline & Past 30 Days & 13.1 & (18) & 4.1 & (1) & 9.9 & (2) & 18.7 & $(4)$ & 15.9 & $(5)$ & 15.1 & $(6)$ & 6.9 & (1) \\
\hline & Past 90 Days & 10.3 & (14) & 11.4 & (2) & 0.9 & $(0)$ & 0.0 & () & 16.1 & $(5)$ & 15.9 & $(7)$ & 5.2 & (1) \\
\hline & Past 12 Months (Year) & 5.0 & (7) & 8.4 & (1) & 13.1 & (2) & 0.0 & () & 2.2 & $(1)$ & 4.0 & $(2)$ & 7.2 & (1) \\
\hline & More than a Year Ago & 12.2 & (16) & 7.2 & (1) & 14.9 & (3) & 2.0 & $(1)$ & 9.3 & (3) & 18.0 & $(7)$ & 20.7 & (2) \\
\hline Used a Lubricant during Foreplay or Sexual & Ever Used & 56.4 & (76) & 54.3 & (9) & 46.8 & (9) & 54.2 & (11) & 54.7 & (16) & 64.0 & (26) & 56.3 & (5) \\
\hline \multirow[t]{4}{*}{ Play with a Partner } & Past 30 Days & 17.4 & (23) & 31.6 & (5) & 9.1 & (2) & 9.8 & $(2)$ & 23.1 & $(7)$ & 15.4 & $(6)$ & 13.7 & (1) \\
\hline & Past 90 Days & 4.1 & (6) & 1.9 & () & 9.2 & (2) & 0.5 & (1) & 8.9 & (3) & 0.8 & $(0)$ & 5.2 & 0 \\
\hline & Past 12 Months (Year) & 7.0 & (9) & 11.7 & (2) & 5.0 & (1) & & & 9.9 & (3) & 6.7 & (3) & 8.8 & (1) \\
\hline & More than a Year Ago & 28.0 & (38) & 9.1 & (2) & 23.5 & (4) & 44.0 & $(9)$ & 12.8 & $(4)$ & 41.1 & (17) & 28.5 & (3) \\
\hline \multirow[t]{5}{*}{ Used a Lubricant during Partnered Intercourse } & Ever Used & 53.0 & (71) & 58.6 & (10) & 46.8 & (9) & 55.8 & (12) & 42.7 & (13) & 59.3 & (23) & 56.2 & (5) \\
\hline & Past 30 Days & 16.0 & (21) & 30.8 & (5) & 12.1 & (2) & 8.0 & $(2)$ & 18.2 & $(5)$ & 15.9 & $(6)$ & 7.1 & (1) \\
\hline & Past 90 Days & 8.5 & (11) & 6.4 & (1) & 9.7 & (2) & 0.5 & $(1)$ & 5.0 & $(1)$ & 16.8 & $(7)$ & 2.9 & () \\
\hline & Past 12 Months (Year) & 9.0 & (12) & 10.5 & (2) & 5.0 & (1) & 25.7 & (5) & 6.8 & $(2)$ & 4.2 & (2) & 6.4 & (1) \\
\hline & More than a Year Ago & 19.5 & $(26)$ & 11.0 & (2) & 20.0 & (4) & 21.6 & $(4)$ & 12.7 & $(4)$ & 22.3 & $(9)$ & 39.8 & (4) \\
\hline \multirow[t]{5}{*}{ Used a Lubricant with a Condom } & Ever Used & 32.2 & (43) & 29.9 & (5) & 39.5 & (7) & 16.9 & (3) & 29.9 & (9) & 40.3 & (17) & 26.1 & (2) \\
\hline & Past 30 Days & 2.9 & (4) & 6.0 & (1) & 0.9 & () & - & & 9.3 & (3) & - & & - & \\
\hline & Past 90 Days & 2.7 & (4) & 10.2 & (2) & 0.9 & () & 5.5 & $(1)$ & - & & - & & 6.7 & (1) \\
\hline & Past 12 Months (Year) & 2.3 & (3) & & & 12.0 & (2) & - & & - & & 0.9 & $(1)$ & 6.1 & (1) \\
\hline & More than a Year Ago & 24.3 & (33) & 13.6 & (2) & 25.6 & (5) & 11.5 & $(2)$ & 20.6 & $(6)$ & 39.4 & $(16)$ & 13.3 & (1) \\
\hline \multirow[t]{5}{*}{ Used a Lubricant with a Vibrator } & Ever Used & 44.0 & (59) & 51.9 & (10) & 24.9 & (5) & 25.7 & (5) & 43.9 & (13) & 55.9 & (22) & 55.3 & (5) \\
\hline & Past 30 Days & 12.1 & (16) & 6.8 & (1) & 16.5 & (3) & 5.8 & $(1)$ & 14.1 & $(4)$ & 15.0 & $(6)$ & 6.7 & (1) \\
\hline & Past 90 Days & 8.1 & (11) & 29.0 & (5) & 1.3 & () & 7.2 & $(1)$ & 9.6 & (3) & 1.2 & () & 9.8 & (1) \\
\hline & Past 12 Months (Year) & 9.4 & (12) & 1.2 & (1) & 5.6 & (1) & - & & 8.6 & (3) & 18.8 & $(8)$ & 13.5 & (1) \\
\hline & More than a Year Ago & 14.5 & (19) & 15.0 & (3) & 1.5 & () & 12.7 & $(2)$ & 11.5 & (3) & 20.9 & $(8)$ & 25.3 & (2) \\
\hline
\end{tabular}


Lesbian and bisexual women, 20

Used a Lubricant with a Dildo
Ever Used

Past 30 Days

Past 90 Days

Past 12 Months (Year)

More than a Year Ago $\begin{array}{lll}18.4 & \text { (25) } \quad 13.7\end{array}$

$\begin{array}{lll}6.9 & \text { (9) } \quad 2.8\end{array}$

(33) 12.2

24.5

$\begin{array}{llll}(7) & 47.7 & (9) & 63.7\end{array}$

$\begin{array}{lll}\text { (2) } & 19.8 & \text { (4) } 23.0\end{array}$

$\begin{array}{lll}\text { (1) } 5.5 & \text { (1) } 5.9\end{array}$

(2) 8.0

$\begin{array}{ll}\text { (2) } & 8.0 \\ \text { (2) } & 14.4\end{array}$

(1) 34

$\begin{array}{lll}\text { (12) } & 61.5 & \text { (18) } \quad 59.4\end{array}$

$\begin{array}{lll}\text { (4) } & 24.9 & \text { (7) } 16.6\end{array}$

$\begin{array}{ccccccc}\text { (4) } & 24.9 & (7) & 16.6 & (7) & 1.1 & () \\ \text { (1) } & 14.6 & (4) & 3.3 & (1) & 10.1 & (1)\end{array}$

\begin{tabular}{ll} 
(24) $\quad 49.1 \quad$ (4) \\
\hline
\end{tabular}

$\begin{array}{lllll}7.7 & (2) & 3.9 & \text { (2) } & 9.3\end{array}$

$\begin{array}{ccc}(2) & 9.3 & (1) \\ \text { (15) } & 28.6 & (3)\end{array}$


Table 2b. Weighted Lifetime and Recency of Lubricant use during Sexual Contexts among Bisexual Identified Women.

\begin{tabular}{|c|c|c|c|c|c|c|c|c|c|c|c|c|c|c|c|}
\hline \multirow{3}{*}{ Recency of Lubricant Use } & & \multicolumn{14}{|c|}{ Bisexual } \\
\hline & & \multicolumn{2}{|c|}{ Total Sample } & \multicolumn{2}{|c|}{$18-24$} & \multicolumn{2}{|c|}{$25-29$} & \multicolumn{2}{|c|}{$30-39$} & \multicolumn{2}{|c|}{$40-49$} & \multicolumn{2}{|c|}{$50-59$} & \multicolumn{2}{|c|}{$60+$} \\
\hline & & & & \multicolumn{12}{|c|}{$\%(N)$} \\
\hline \multirow[t]{5}{*}{ Used a Lubricant } & Ever Used & 77.1 & $(\mathbf{1 7 0})$ & 79.5 & (45) & 71.5 & (32) & 83.1 & $(52)$ & 82.6 & (24) & 62.3 & (14) & 63.4 & (4) \\
\hline & Past 30 Days & 32.7 & $(72)$ & 46.5 & $(26)$ & 25.1 & (11) & 22.2 & $(14)$ & 48.7 & $(14)$ & 22.4 & $(5)$ & 30.5 & (2) \\
\hline & Past 90 Days & 12.5 & (28) & 10.4 & $(6)$ & 10.6 & $(5)$ & 21.5 & (13) & 6.3 & (2) & 7.6 & (2) & 3.5 & () \\
\hline & Past 12 Months (Year) & 11.8 & $(26)$ & 10.3 & $(6)$ & 21.6 & $(10)$ & 7.5 & $(5)$ & 8.1 & $(2)$ & 14.3 & (3) & 5.9 & () \\
\hline & More than a Year Ago & 20.0 & $(44)$ & 12.2 & $(7)$ & 14.2 & $(6)$ & 31.8 & $(20)$ & 19.5 & (6) & 18.0 & $(4)$ & 23.4 & $(2)$ \\
\hline \multirow[t]{5}{*}{ Used a Lubricant during Solo Masturbation } & Ever Used & 47.7 & $(105)$ & 47.5 & (27) & 52.9 & (24) & 42.9 & $(27)$ & 47.2 & $(13)$ & 48.9 & (11) & 56.0 & (4) \\
\hline & Past 30 Days & 18.8 & $(41)$ & 31.0 & $(18)$ & 8.0 & $(4)$ & 15.5 & $(10)$ & 22.7 & (6) & 11.6 & (3) & 26.2 & (2) \\
\hline & Past 90 Days & 11.4 & (25) & 4.1 & $(2)$ & 21.7 & (10) & 10.1 & (6) & 14.1 & (4) & 7.6 & (2) & 16.6 & (1) \\
\hline & Past 12 Months (Year) & 5.3 & $(12)$ & 4.2 & $(2)$ & 4.4 & $(2)$ & 7.4 & (5) & 1.0 & () & 10.0 & (2) & 1.8 & () \\
\hline & More than a Year Ago & 12.3 & $(27)$ & 8.3 & $(5)$ & 18.9 & $(9)$ & 9.8 & (6) & 9.3 & (3) & 19.8 & (4) & 11.3 & (1) \\
\hline Used a Lubricant during Foreplay or Sexual & Ever Used & 61.4 & (136) & 52.9 & (30) & 57.0 & (26) & 63.8 & $(40)$ & 77.9 & $(23)$ & 56.6 & (12) & 87.4 & (6) \\
\hline \multirow[t]{4}{*}{ Play with a Partner } & Past 30 Days & 18.0 & $(40)$ & 24.9 & $(14)$ & 19.4 & $(9)$ & 10.9 & (7) & 32.1 & (9) & 3.6 & (1) & 2.5 & () \\
\hline & Past 90 Days & 9.1 & $(20)$ & 9.7 & $(6)$ & 2.7 & $(1)$ & 15.6 & $(10)$ & 5.4 & $(2)$ & 10.0 & $(2)$ & 1.8 & () \\
\hline & Past 12 Months (Year) & 10.1 & $(22)$ & 13.0 & (7) & 8.9 & $(4)$ & 4.5 & (3) & 18.2 & (5) & 7.2 & (2) & 21.0 & $(1)$ \\
\hline & More than a Year Ago & 24.1 & $(54)$ & 5.2 & $(3)$ & 26.0 & $(12)$ & 32.9 & $(20)$ & 22.3 & $(6)$ & 35.8 & (8) & 62.1 & (4) \\
\hline \multirow[t]{5}{*}{ Used a Lubricant during Partnered Intercourse } & Ever Used & 64.7 & $(144)$ & 59.5 & (34) & 70.1 & (32) & 66.9 & $(41)$ & 71.9 & (21) & 51.3 & (11) & 65.4 & (4) \\
\hline & Past 30 Days & 20.7 & $(46)$ & 30.8 & $(18)$ & 18.0 & (8) & 14.4 & (9) & 33.0 & $(10)$ & 6.5 & (1) & 2.5 & () \\
\hline & Past 90 Days & 10.3 & $(23)$ & 7.4 & $(4)$ & 7.9 & $(4)$ & 15.1 & (9) & 9.1 & (3) & 13.8 & (3) & 1.8 & () \\
\hline & Past 12 Months (Year) & 10.1 & $(22)$ & 13.5 & (8) & 13.1 & $(6)$ & 4.2 & (3) & 16.1 & (5) & 5.3 & (1) & 3.5 & () \\
\hline & More than a Year Ago & 23.6 & $(52)$ & 7.9 & $(4)$ & 31.1 & $(14)$ & 33.1 & $(21)$ & 13.6 & (4) & 25.7 & (6) & 57.6 & (4) \\
\hline \multirow[t]{5}{*}{ Used a Lubricant with a Condom } & Ever Used & 49.2 & $(108)$ & 47.5 & (27) & 51.9 & (23) & 52.0 & $(32)$ & 62.0 & (18) & 30.1 & (6) & 23.9 & (2) \\
\hline & Past 30 Days & 5.2 & $(11)$ & 12.1 & $(7)$ & 1.5 & $(1)$ & 0.8 & $(1)$ & 9.4 & (3) & 3.1 & (1) & - & \\
\hline & Past 90 Days & 6.2 & $(14)$ & 1.0 & (1) & 16.2 & $(7)$ & 9.5 & (6) & - & & - & & - & \\
\hline & Past 12 Months (Year) & 7.3 & $(16)$ & 10.7 & (6) & 8.4 & $(4)$ & 8.2 & $(5)$ & 2.9 & $(1)$ & - & & 4.3 & () \\
\hline & More than a Year Ago & 30.5 & $(67)$ & 23.6 & $(13)$ & 25.8 & $(12)$ & 33.5 & $(20)$ & 49.7 & $(14)$ & 27.0 & (6) & 19.6 & $(1)$ \\
\hline \multirow[t]{5}{*}{ Used a Lubricant with a Vibrator } & Ever Used & 48.8 & $(108)$ & 36.4 & (21) & 55.0 & (25) & 51.4 & $(32)$ & 68.9 & $(20)$ & 32.2 & (7) & 54.6 & (4) \\
\hline & Past 30 Days & 14.3 & (32) & 14.8 & (8) & 11.5 & $(5)$ & 13.7 & (8) & 23.7 & (7) & 4.1 & (1) & 27.6 & $(2)$ \\
\hline & Past 90 Days & 5.2 & (11) & 4.5 & (3) & 6.0 & $(3)$ & 7.5 & (5) & 2.4 & (1) & 1.0 & & 8.6 & (1) \\
\hline & Past 12 Months (Year) & 10.4 & $(23)$ & 2.4 & $(1)$ & 18.9 & $(9)$ & 11.2 & (7) & 20.2 & (6) & - & & 3.9 & () \\
\hline & More than a Year Ago & 19.0 & (42) & 14.7 & (8) & 18.7 & (8) & 19.0 & (12) & 22.6 & (7) & 27.2 & (6) & 14.5 & (1) \\
\hline
\end{tabular}




\begin{tabular}{lcccccccccccccc} 
Ever Used & $\mathbf{5 2 . 0}$ & $\mathbf{( 1 1 6 )}$ & $\mathbf{4 2 . 0}$ & $\mathbf{( 2 4 )}$ & $\mathbf{5 5 . 3}$ & $\mathbf{( 2 5 )}$ & $\mathbf{5 1 . 1}$ & $\mathbf{( 3 2 )}$ & $\mathbf{6 9 . 8}$ & $\mathbf{( 2 0 )}$ & $\mathbf{5 2 . 2}$ & $\mathbf{( 1 2 )}$ & $\mathbf{4 7 . 1}$ & $\mathbf{( 3 )}$ \\
Past 30 Days & 15.0 & $(33)$ & 22.5 & $(13)$ & 11.9 & $(5)$ & 12.6 & $(8)$ & 17.9 & $(5)$ & 7.7 & $(2)$ & 4.0 & 0 \\
Past 90 Days & 7.4 & $(16)$ & 0.6 & () & 8.3 & $(4)$ & 14.9 & $(9)$ & 6.6 & $(2)$ & 4.0 & $(1)$ & 2.6 & () \\
Past 12 Months (Year) & 10.0 & $(22)$ & 5.0 & $(3)$ & 15.5 & $(7)$ & 4.8 & $(3)$ & 18.3 & $(5)$ & 17.7 & $(4)$ & 1.8 & 0 \\
More than a Year Ago & 19.7 & $(44)$ & 13.8 & $(8)$ & 19.5 & $(9)$ & 18.9 & $(12)$ & 26.9 & $(8)$ & 22.7 & $(5)$ & 38.7 & $(3)$ \\
\hline
\end{tabular}


Table 3. Weighted Frequency of Lubricant Used for Participants who Reported Lubricant Use in the Following Contexts within the Past 90 Days.

\begin{tabular}{|c|c|c|c|c|c|}
\hline \multirow{2}{*}{ Recency of Lubricant Use } & & \multicolumn{2}{|c|}{ Bisexual } & \multicolumn{2}{|c|}{ Lesbian } \\
\hline & & \multicolumn{2}{|c|}{$\%(\mathrm{~N})$} & \multicolumn{2}{|c|}{$\%(N)$} \\
\hline \multirow[t]{4}{*}{ Used a Lubricant } & Once or Twice & 33.71 & $(12)$ & 33.28 & (29) \\
\hline & 3-5 Times & 11.54 & $(4)$ & 26.71 & (24) \\
\hline & 6-10 Times & 27.25 & (9) & 15.32 & (14) \\
\hline & More than 10 Times & 27.49 & $(10)$ & 24.69 & (22) \\
\hline \multirow[t]{4}{*}{ Used a Lubricant during Solo Masturbation } & Once or Twice & 17.64 & (5) & 40.33 & (24) \\
\hline & 3-5 Times & 28.74 & (8) & 23.00 & (14) \\
\hline & 6-10 Times & 13.95 & (4) & 15.56 & (9) \\
\hline & More than 10 Times & 39.67 & $(12)$ & 21.11 & (13) \\
\hline \multirow[t]{4}{*}{ Used a Lubricant during Partnered Sexual Play } & Once or Twice & 33.10 & $(10)$ & 31.26 & (17) \\
\hline & 3-5 Times & 16.71 & (5) & 34.37 & (19) \\
\hline & 6-10 Times & 39.28 & $(11)$ & 13.14 & $(7)$ \\
\hline & More than 10 Times & 10.91 & (3) & 21.23 & $(12)$ \\
\hline \multirow[t]{4}{*}{ Used a Lubricant during Partnered Intercourse } & Once or Twice & 26.00 & (8) & 40.97 & (25) \\
\hline & 3-5 Times & 10.63 & (3) & 13.17 & (8) \\
\hline & 6-10 Times & 25.09 & (8) & 9.93 & (6) \\
\hline & More than 10 Times & 38.27 & $(12)$ & 35.92 & $(22)$ \\
\hline \multirow[t]{4}{*}{ Used a Lubricant with a Condom } & Once or Twice & 41.45 & (3) & 50.90 & (12) \\
\hline & 3-5 Times & 50.31 & (4) & 7.40 & (2) \\
\hline & 6-10 Times & - & - & 14.42 & (3) \\
\hline & More than 10 Times & 8.24 & (1) & 27.28 & (7) \\
\hline \multirow[t]{4}{*}{ Used a Lubricant with a Vibrator } & Once or Twice & 24.11 & (5) & 38.79 & (15) \\
\hline & 3-5 Times & 24.29 & (5) & 25.76 & (10) \\
\hline & 6-10 Times & 15.26 & (3) & 12.77 & (5) \\
\hline & More than 10 Times & 36.33 & (8) & 22.67 & (9) \\
\hline \multirow[t]{4}{*}{ Used a Lubricant with a Dildo } & Once or Twice & 28.61 & (9) & 40.45 & (16) \\
\hline & 3-5 Times & 18.20 & $(6)$ & 19.06 & (8) \\
\hline & 6-10 Times & 30.10 & $(10)$ & 23.91 & (10) \\
\hline & More than 10 Times & 23.10 & $(7)$ & 16.58 & $(7)$ \\
\hline
\end{tabular}


Table 4. Weighted Lubricant Use Reasons for Lubricant Use by Sexual Orientation

\begin{tabular}{|c|c|c|c|c|}
\hline \multirow{3}{*}{ Reason for First Starting Use } & \multirow{2}{*}{\multicolumn{2}{|c|}{$\begin{array}{c}\begin{array}{c}\text { Bisexual } \\
(\mathbf{N}=170)\end{array} \\
\%(\mathrm{~N})\end{array}$}} & \multicolumn{2}{|c|}{$\begin{array}{c}\text { Lesbian } \\
(\mathrm{N}=61)\end{array}$} \\
\hline & & & \multicolumn{2}{|c|}{$\%(N)$} \\
\hline & & & & \\
\hline Curiosity & 42.4 & $(72)$ & 30.0 & $(23)$ \\
\hline For fun & 39.9 & $(68)$ & 40.9 & $(31)$ \\
\hline To make sex more comfortable & 38.4 & $(65)$ & 57.3 & $(44)$ \\
\hline To enhance foreplay & 33.2 & $(57)$ & 26.2 & $(20)$ \\
\hline My partner wanted us to & 28.4 & $(48)$ & 31.6 & $(24)$ \\
\hline To add pleasurable sensations to sex & 24.8 & $(42)$ & 29.6 & $(23)$ \\
\hline To make sex feel more wet & 23.8 & $(41)$ & 29.9 & $(23)$ \\
\hline To comfortably have anal sex & 19.3 & (33) & 8.5 & $(6)$ \\
\hline To spice up my/our sex life & 14.9 & $(25)$ & 7.3 & $(6)$ \\
\hline A friend said it was fun to use & 13.1 & (22) & 2.7 & (2) \\
\hline To manage vaginal pain & 11.6 & $(20)$ & 15.1 & $(12)$ \\
\hline To reduce the risk of tearing & 8.2 & $(14)$ & 1.7 & $(1)$ \\
\hline To reduce the risk of condom breakage & 6.2 & $(11)$ & 0.0 & $(0)$ \\
\hline My (or my partner's) body changed during pregnancy & 3.3 & (6) & 0.0 & $(0)$ \\
\hline Other & 3.3 & (6) & 2.9 & $(2)$ \\
\hline Approaching menopause & 1.7 & (3) & 10.3 & $(8)$ \\
\hline Because of medication use/surgery & 1.1 & (2) & 10.0 & $(8)$ \\
\hline While post-partum/nursing & 0.3 & (1) & 0.0 & $(0)$ \\
\hline \multicolumn{5}{|l|}{ Reason for First Starting use during Sexual Activities } \\
\hline My partner suggested we use lubricant & 40.8 & $(70)$ & 48.2 & $(37)$ \\
\hline I wanted to make sex more pleasurable & 29.7 & $(51)$ & 40.7 & $(31)$ \\
\hline I wanted to reduce discomfort or pain during sex & 22.2 & $(38)$ & 29.4 & $(22)$ \\
\hline A friend recommended lubricant & 15.5 & $(26)$ & 8.9 & $(7)$ \\
\hline I saw an advertisement for lubricant & 13.6 & $(23)$ & 7.8 & $(6)$ \\
\hline I noticed that lubricated condoms felt more comfortable & 8.4 & $(14)$ & 2.1 & $(2)$ \\
\hline Other & 5.8 & $(10)$ & 7.5 & $(6)$ \\
\hline A family member recommended lubricant & 4.6 & (8) & 1.1 & $(1)$ \\
\hline A doctor or nurse recommended lubricant & 2.8 & (5) & 2.7 & (2) \\
\hline A health educator or sex educator recommended lubricant & 1.2 & (2) & 7.0 & $(5)$ \\
\hline
\end{tabular}


Table 5. Perceptions of Lubricant Use by Age using Post-Stratification Weights.

\begin{tabular}{|c|c|c|c|c|c|c|c|c|c|c|c|}
\hline \multirow{3}{*}{ Using lubricant during sexual activities... } & \multicolumn{5}{|c|}{ Bisexual $(\mathrm{N}=167)$} & \multicolumn{6}{|c|}{ Lesbian $(\mathrm{N}=75)$} \\
\hline & \multirow{2}{*}{$\begin{array}{c}\% \\
\text { Disagree }\end{array}$} & \multirow{2}{*}{$\begin{array}{c}\% \\
\text { Agree }\end{array}$} & \multirow{2}{*}{\multicolumn{3}{|c|}{$\begin{array}{c}\text { Age by Statement } \\
\text { Agreement } \\
\text { Odds Ratio }(95 \% \mathrm{Cl})\end{array}$}} & \multirow{2}{*}{$\begin{array}{c}\% \\
\text { Disagree }\end{array}$} & \multirow{2}{*}{$\begin{array}{c}\% \\
\text { Agree }\end{array}$} & \multicolumn{4}{|c|}{$\begin{array}{l}\text { Age by Statement } \\
\text { Agreement } ~\end{array}$} \\
\hline & & & & & & & & \multicolumn{4}{|c|}{ Odds Ratio (95\% Cl) } \\
\hline Makes it easier to feel aroused. & 39.5 & 60.5 & 1.02 & & $(.99-1.05)$ & 24.4 & 75.6 & 1.03 & & $(.99-$ & 1.08) \\
\hline Makes it easier to have an orgasm. & 50.9 & 49.1 & 1.00 & & $(.97-1.03)$ & 32.9 & 67.1 & 1.02 & & $(.99-$ & 1.06) \\
\hline Makes sex feel better. & 34.3 & 65.7 & 1.05 & ** & $(1.01-\quad 1.08)$ & 15.4 & 84.6 & 1.03 & & $(.98-$ & 1.08) \\
\hline Makes sex more comfortable. & 19.3 & 80.7 & 1.02 & & $(.98-1.05)$ & 12.3 & 87.7 & 1.11 & $* * *$ & $(1.03-$ & 1.19) \\
\hline
\end{tabular}

${ }^{\star} p \leq .05,{ }^{* \star} p \leq .01,{ }^{* * *} p \leq .005,{ }^{* * *} p \leq .001$. An odds ratio over 1.0 indicates increased agreement with the statement for every one year in age. 